\author{
Military Technical College \\ Kobry Elkobbah, \\ Cairo, Egypt
}

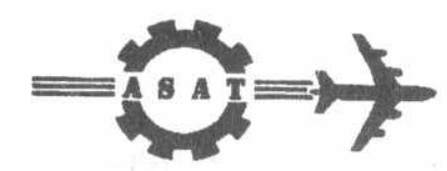

$8^{\text {th }}$ International Conference on Aerospace Sciences \& Aviation Technology

\title{
AN ANALYTICAL MODEL FOR COMPOSITE BOX-BEAMS
}

\author{
M.M. EL NOMROSSY", A.H. ESMAT**
}

\begin{abstract}
A direct analytical beam formulation is developed for predicting the effective elastic stiffnesses and corresponding load deformation behavior of tailored box beams. Deformation of the beam is described by extension, bending, torsion, transverse shearing, and torsion related out-of-plane warping. The present analysis is developed without much dependence on thin-walled beam theory. Formulation of the analysis is in terms of a two-dimensional cross-section, instead of an infinitely thin contour enable stresses, strains, elastic properties to vary through the thickness of the beam walls in a manner consistent to the true laminated structure nature of the composite structure. This analytical model is very useful in studying non-classical phenomenon such as warping and in-plane elasticity. Governing differential equations for the extension, bending, torsion and shearing of the beam are derived using Newtonian approach. Validation studies are carried out for composite designs with no coupling, designs with varying degrees of extension-torsion and bending shear coupling, as well as designs with varying degrees of torsion- bending and extension shear coupling. The analysis is evaluated by correlation with existing experimental results.
\end{abstract}

\section{KEY WORDS}

Composite Structures, Thin-Walled Structures, Aeroelastic Tailoring, Box-Beam Analysis.

\footnotetext{
* Professor, Dpt. of Aerospace Engineering, M.T.C, Cairo, Egypt.

${ }^{\star *}$ Engineer, Dpt. of Machine Design, , M.T.C, Cairo, Egypt.
} 


\section{INTRODUCTION}

The benefits of advanced composite materials and a box-beam construction have been widely recognized by the aerospace community. Many primary structural components such as aircraft wing spars and the helicopter rotor blades now feature composite box-beam designs. These composite designs are lightweight and offer innovative characteristics, however, the inherit tailorability of composite structures has not been fully taken advantage of. In particular, the elastic coupling between several of deformations are typically not exploited in composite designs. These couplings such as bending-torsion and extension-torsion arise due to the anistropic or directional nature of fibrous composites. One of the most dramatic applications of this technology is the bending-torsion coupled composite structure to prevent divergence of swept-forward wings. Successful applications of composite box-beam structures require the development of new analytical tools, which are both sufficiently accurate and computationally efficient.

Recent efforts toward the creation of new analytical tool for composite bearns have led to the development of several finite element based methods. The finite element models provide varying degrees of analytical flexibility depending on the level of computational level required. Detailed finite element formulations have been used to capture a variety of non-classical phenomenon in composite beams and blades. For example, Borriet et al, [1], Bauchau and Hong, [2,3], and Stemple and Lee, [4], have investigated the effects of warping and large displacements wing specially designed beam finite elements or combinations of isoparametric elements. Although these methods are quite powerful, a certain amount of physical insight is often sacrificed in the formulation and the implementation of large scale discertized numerical solution. A number of direct analytical methods have also been formulated for thin-walled composite beams. Reissner and Tsai [5] developed shell analysis for bending, stretching and twisting of composite shell structure. Mansfield and Sobey [6], developed a simple thin walled contour analysis and introduced the coricept of aeroelastically tailored composite helicopter rotor blade. Bauchau [7] has also developed a thin-walled contour formulation using a refined approach to warping. Bicos and Springer [8] investigated the minimum weight design of a semi-monocoque (stringer and webs) composite box-beam using a reduced plate model. Libove [9] has also developed a thin-walled contour analysis, which is similar to the work of Mansfield and Sobey [6]. These direct analytical methods are typically based on assumptions are made in order to obtain governing differential equations without discretizing the entire problem. In some cases the governing equations can then been solved directly [9]. Variational principles are to be used to determine approximate solutions $[7,8]$. In addition to computational simplicity and speed, analytical formulations can provide valuable cause effect relationships and enhance analytical formulations can provicitic understanding of non-classical phenomenon and elastic coupling effects.
physical
Despite the increased appearance of the aforementioned finite element and direct analytical methods during the past decade, the structural behavior of composite boxbeam is not yet thoroughly understood. Many of the methods which have been previously developed, especially the direct analytical methods, do not address all the non-classical effects, consequently, the importance of many non-classical structural phenomenon associated with composite box-beam construction has not been clearly established and quantified. 
The objectives of this study are: -

1- To develop a direct analytical method for predicting the effective elastic stiffness and corresponding load deformation behavior of composite box-beam.

2- To validate and evaluate analytical method.

3- To apply the new analysis to examine the importance of non-classical structural phenomenon.

A systematic approach is taken to develop both a qualitative and quantitative understanding of composite box-beam behavior. Special consideration is given to modeling the effects of anisotropy elasticity, laminated construction, torsion related warping, and transverse shear. Correlating the analytical results with the experimental results carries out evaluation of analytical method. The analysis is then is then applied to investigate the non-classical phenomenon such as warping, transverse shear and transverse in-plane elasticity.

The deformation of box-beam is described by extension, bending, twisting, shearing, and torsion related out-of-plane warping. The composite walls of the rectangular boxbeam are represented as four laminated plates, which are built up by layers of orthotropic plies. Unlike the box-beam beams, which are constructed using isotropic materials, the elastic properties of the laminated composite box-beam designs generally vary both through the thickness and along the contour of the beam crosssection. This unique distribution of stiffness enhances the tailorability of composite structures. By varying the ply lay-up within the beam walls (fiber orientation angles, stacking sequence, ply material, etc.) structural designers can create elastic couplings between deformations such as extension and torsion, bending torsion, or

Many of the current direct analytical methods for composite beams are based heavily on thin-walled beam theory [9]. Variations in stresses, strains and elastic properties through the thickness of the laminated beam walls must be treated in an approximate manner, which can be break down as wall thickness increases. The present analysis is developed without much dependence on thin-walled beam theory. Formulation of the analysis in terms of a two dimensional cross-section, instead of infinitely thin contour enables stresses, strains, and elastic properties to vary through the thickness of the beam walls in manner consistent the true laminated composite structure. This analytical detail is very useful in studying non-classical phenomenon such as warping

Governing differential equations for extension, bending, torsion and shearing of the beam are derived using Newtonian approach. This method, in which applied forces and moments over the cross-section are reacted by the stresses within the beam walls, is very commonly applied in formal elasticity solutions. Another key element for the composite beam formulation is the manner in which two-dimensional anistropic elastic behavior of the beam walls is captured by one-dimensional beam theory. In other words Poison's effect can become more significant for certain composite designs. Both the strain-displacement and stress-strain relations are important to this critical issue. Methods for bridging this analytical gap are investigated and evaluated. 


\section{FORMULATION OF ANALYTICAL MODEL}

The box-bearn geometry and coordinates are shown in Fig.1
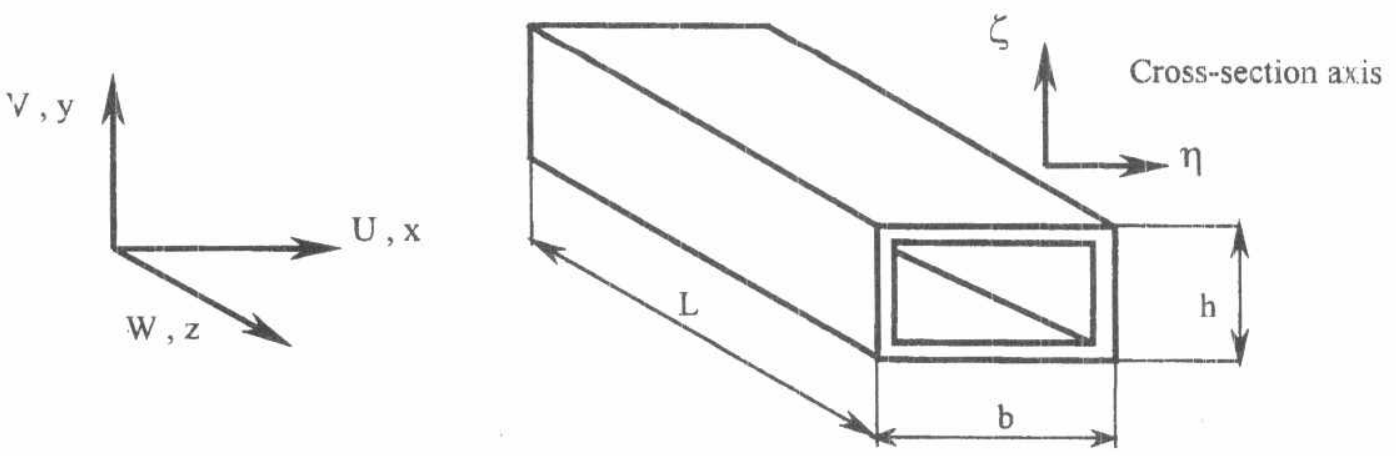

Fig(1): Box-beam Configuration

The cross-section axis origin is at the center of the beam section. The deformation of the beam cross-section is described by stretching, bending, twisting, shearing and warping. Therefore, the total beam displacements are given in the form: -

Total horizontal deformation

$$
\mathrm{U}=\mathrm{u}(\mathrm{z})-\zeta \varphi(\mathrm{z})
$$

Total vertical deformation

$$
\mathrm{V}=\mathrm{v}(\mathrm{z})-\eta \varphi(\mathrm{z})
$$

Total axial deformation

$$
\mathrm{W}=\mathrm{w}(\mathrm{z})-\eta\left(\mathrm{u}^{\prime}(\mathrm{z})-\gamma_{\mathrm{xz}}(\mathrm{z})\right)-\zeta\left(\mathrm{v}^{\prime}(\mathrm{z})-\gamma_{\mathrm{yz}}(\mathrm{z})\right)-\omega(\mathrm{s}) \varphi^{\prime}(\mathrm{z})
$$

It should be noted that the term "warping" represents the out-of-plane axial displacement of the cross-section due to torsional deformation. This is commonly referred to as torsion-related warping. In the present analysis, the thin-walled beam theory, for free warping is modified to determine the shape of the warping deflections for a composite box-beam. The warping function is then transformed from contour form to two dimensional cross-section form the warping function is then carried through the entire analysis, from the initial kinematics relations to the effective stiffness of the beam cross-section. It is important to note that this is the only point in the analysis when the cross-section is treated on the contour level of the thin-walled beam theory.

The warping function is defined along the contour as: -

$$
\omega(s)=2 A\left(\frac{\delta_{\text {os }}}{\delta}-\frac{A_{\text {os }}}{A}\right)
$$

The enclosed area of the cross-section, $\mathrm{A}$ is: -

$$
A=b h
$$

and the other contour parameters are defined as:-

$$
\begin{aligned}
\delta & =\oint_{s} \frac{d s}{G(s) t(s)} \\
\delta_{\text {os }} & =\int_{0}^{s} \frac{d s}{G(s) t(s)}
\end{aligned}
$$


and $A_{o s}$ is the area swept out by a generator, with origin at the box-beam center, from $s=0$ to $s=s$ on the contour.

After evaluating all line integrals around the cross-section, around the cross-section, the warping function, $\omega(\mathrm{s})$, can be transformed into the two dimensional cross-section Form: -

where

$$
\omega(\eta, \zeta)=\beta \eta \zeta
$$

$$
\beta=\frac{1-\alpha}{1+\alpha}
$$

and the coefficient $\alpha$ is given by:

$$
\alpha=\left(\frac{b}{h}\right)\left(\frac{t_{v}}{t_{h}}\right)\left(\frac{G_{v}}{G_{h}}\right)
$$

At this point, effective in-plane shear stiffness for the composite box-beam walls must be specified. Consider a single beam wall as a laminated plate. The relations between in-plane stress resultant $N_{x}, N_{y}, N_{x y}$ and in-plane strains $\varepsilon_{x}{ }^{\circ} \varepsilon_{y}{ }^{\circ} \varepsilon_{x y}{ }^{\circ}$ are

$$
\left\{\begin{array}{c}
N_{x} \\
N_{y} \\
N_{x y}
\end{array}\right\}=\left[\begin{array}{lll}
A_{11} & A_{12} & A_{13} \\
A_{12} & A_{22} & A_{23} \\
A_{13} & A_{23} & A_{33}
\end{array}\right]\left\{\begin{array}{c}
\varepsilon_{x}^{o} \\
\varepsilon_{y}^{o} \\
\varepsilon_{x y}^{o}
\end{array}\right\}
$$

With

$$
A_{i j}=\sum_{p=1}^{N}\left(t_{p}\right)\left(\bar{Q}_{i j}\right)
$$

The elements of the ply stiffness matrix, $\bar{Q}_{i j}$ are defined in texts discussing the macromechanical behavior of composite plies[10]. These stiffness coefficients are functions of ply orientation angle $\theta$. If transverse in-plane stress resultant, $N_{y}$, is assumed small for beam structures, then the stiffness matrix reduces to

$$
A^{\prime}=\left[\begin{array}{ll}
{\left[A_{11}-\frac{\left(A_{12}\right)^{2}}{A_{22}}\right]} & {\left[A_{13}-\frac{A_{12} A_{23}}{A_{22}}\right]} \\
{\left[A_{13}-\frac{A_{12} A_{23}}{A_{22}}\right]} & {\left[A_{11}-\frac{\left(A_{26}\right)^{2}}{A_{22}}\right]}
\end{array}\right]=\left[\begin{array}{ll}
A_{11}^{\prime} & A_{13}^{\prime} \\
A_{13}^{\prime} & A_{33}^{\prime}
\end{array}\right]
$$

The effective in-plane shear stiffness can be defined by considering the shear strain, $\varepsilon_{\mathrm{xy}}{ }^{\circ}$ which results from an applied shear force resultant, $N_{\mathrm{xy}}$

$$
G_{\text {eff }}=t_{w}\left(A_{33}^{\prime}-\frac{\left(A_{13}^{\prime}\right)^{2}}{A_{11}^{\prime} A_{33}^{\prime}}\right)
$$

The strains are determined by differentiating the above displacements terms. At this points, the walls of the box-beam are assumed to be relatively thin, therefore, only axial and in-plane shear strains exist and all other components are neglected. The resulting strains are: - In the horizontal walls:

$$
\begin{aligned}
& \varepsilon_{\mathrm{zz}}=\frac{\partial \mathrm{W}}{\partial \mathrm{z}}=\mathrm{w}^{\prime}-\eta\left(\mathrm{u}^{\prime \prime}-\gamma_{\mathrm{zx}}^{\mathrm{o}}\right)-\zeta\left(\mathrm{v}^{\prime \prime}-\gamma_{\mathrm{zy}}^{0}\right)-\omega^{\prime \prime} \\
& \varepsilon_{\mathrm{zx}}=\frac{\partial \mathrm{W}}{\partial \zeta}+\frac{\partial \mathrm{U}}{\partial \mathrm{z}}=-\left(\zeta+\frac{\partial \omega}{\partial \eta}\right) \varphi^{\prime}+\gamma_{\mathrm{zx}}^{\circ}
\end{aligned}
$$


In the vertical walls:

$$
\begin{aligned}
& \varepsilon_{\mathrm{zz}}=\frac{\partial \mathrm{W}}{\partial \mathrm{z}}=\mathrm{w}^{\prime}-\eta\left(\mathrm{u}^{\prime \prime}-\gamma_{\mathrm{zx}}^{\mathrm{o}}\right)-\zeta\left(\mathrm{v}^{\prime \prime}-\gamma_{\mathrm{zy}}^{\circ}\right)-\omega \varphi^{\prime \prime} \\
& \varepsilon_{\mathrm{zx}}=\frac{\partial \mathrm{W}}{\partial \zeta}+\frac{\partial \mathrm{U}}{\partial \mathrm{z}}=\left(\eta-\frac{\partial \omega}{\partial \zeta}\right) \varphi^{\prime}+\gamma_{\mathrm{zx}}^{\mathrm{o}}
\end{aligned}
$$

In the engineering beam theory, the transverse in-plane normal strain does not enter the formulation. This is a natural consequence of the one-dimensional nature of the beam theory itself. However, when the walls of the box beam are made of larninated composite material plies transverse in-plane normal stresses and strains become a quite important. The anistropic elastic characteristics of the composite plies can result in highly two-dimensional elastic behavior. This become more apparent upon considering the stress-strain relationship for a single ply of composite material, generally oriented. Using the notation given in reference [10], the elastic constitutive relations are: -

$$
\left\{\begin{array}{c}
\sigma_{x} \\
\sigma_{y} \\
\sigma_{x y}
\end{array}\right\}=\left[\begin{array}{lll}
\bar{Q}_{11} & \bar{Q}_{12} & \bar{Q}_{13} \\
\bar{Q}_{21} & \bar{Q}_{22} & \bar{Q}_{23} \\
\bar{Q}_{31} & \bar{Q}_{32} & \bar{Q}_{33}
\end{array}\right]\left\{\begin{array}{c}
\varepsilon_{x} \\
\varepsilon_{y} \\
\varepsilon_{x y}
\end{array}\right\}
$$

where

- $\quad$ subscript $x$ denotes stress or strain of the ply in the longitudinal in-plane direction.

- subscript y denotes stress or strain of the ply in the transverse in-plane direction.

- $\quad$ subscript xy denotes stress or strain of the ply in the in-plane direction.

Coupling between extension and in-plane shear within the composite ply is the source of the elastic couplings in composite structures. For unidirectional fiber plies at orientation angles of 0 and 90 degrees, coupling stiffness terms $\bar{Q}_{13}$ and $\bar{Q}_{23}$ are zero. It should be noted that, subscript $y$ in the above notation would correspond to $\eta$ in the horizontal walls and $\zeta$ in the vertical walls. The specific manner in which the two-dimensional nature of composite walls is captured by one-dimensional beam theory is an important issue in the composite box-beam analysis. In the present direct analytical model, three different methods have been examined to haridle this problem.

\section{Method 1:}

The first method is the closest one to the engineering beam theory. It is based on the following: -

- initial kinematic assumptions about the beam deformations $\varepsilon_{y}=0$. and

- $\sigma_{y}$ has no effect on the resultant forces and moments acting on the cross-section.

These conditions result in a simplified form of the ply elastic constitutive relations, given as follows: -

$$
\left\{\begin{array}{c}
\sigma_{x} \\
\sigma_{x y}
\end{array}\right\}=\left[\begin{array}{ll}
\overline{Q_{11}} & \overline{Q_{13}} \\
\overline{\sigma_{\jmath 1}} & Q_{33}
\end{array}\right]\left\{\begin{array}{c}
\varepsilon_{x} \\
\varepsilon_{x y}
\end{array}\right\}
$$


Considering these constitutive relations for the plies of the composite walls of the box-beam, we get the following stress-strain relations for the plies of the beam walls:

- for horizontal walls: -

and

$$
\begin{aligned}
& \sigma_{z z}=\overline{Q_{11}} \varepsilon_{z z}+\overline{Q_{13}} \varepsilon_{z \eta} \\
& \sigma_{z \eta}=\overline{Q_{13}} \varepsilon_{z z}+\overline{Q_{33}} \varepsilon_{z \eta}
\end{aligned}
$$

for vertical walls: -

$$
\begin{aligned}
& \sigma_{z z}=\overline{Q_{11}} \varepsilon_{z z}+\overline{Q_{13}} \varepsilon_{z \zeta} \\
& \sigma_{z \zeta}=\overline{Q_{13}} \varepsilon_{z z}+\overline{Q_{33}} \varepsilon_{z \zeta}
\end{aligned}
$$

Note: $x$-axis in ply notation is identical to $z$-axis in beam notation.

\section{Method 2}

- The second method addressed the transverse in-plane behavior. In this method: $\sigma_{\mathrm{y}}=0$.

and

$-\varepsilon_{\mathrm{y}}$ is removed from the constitutive relation by substitution.

This procedure results in the following modified constitutive relations: -

$$
\left\{\begin{array}{c}
\sigma_{\mathrm{x}} \\
\sigma_{\mathrm{xy}}
\end{array}\right\}=\left[\begin{array}{ll}
\overline{\mathrm{Q}}_{11}^{*} & \overline{\mathrm{Q}}_{13}^{*} \\
\overline{\mathrm{Q}}_{13}^{*} & \overline{\mathrm{Q}}_{33}^{*}
\end{array}\right]\left\{\begin{array}{l}
\varepsilon_{\mathrm{x}} \\
\varepsilon_{\mathrm{xy}}
\end{array}\right\}
$$

where:

$$
\begin{aligned}
& \overrightarrow{\mathrm{Q}}_{11}^{*}=\overline{\mathrm{Q}}_{11}-\frac{\overline{\mathrm{Q}}_{12}^{2}}{\overline{\mathrm{Q}}_{22}} \\
& \overline{\mathrm{Q}}_{13}^{*}=\overline{\mathrm{Q}}_{13}-\frac{\overline{\mathrm{Q}}_{12} \overline{\mathrm{Q}}_{23}}{\overline{\mathrm{Q}}_{22}} \\
& \overline{\mathrm{Q}}_{33}^{*}=\overline{\mathrm{Q}}_{33}-\frac{\overline{\mathrm{Q}}_{23}^{2}}{\overline{\mathrm{Q}}_{22}}
\end{aligned}
$$

Considering these constitutive relations for the plies of the composite walls of the box-beam, we get the following stress-strain relations for the plies of the beam walls:

- For horizontal walls: -

$$
\begin{aligned}
& \sigma_{z z}=\overline{\mathrm{Q}}_{11}^{*} \varepsilon_{z z}+\overline{\mathrm{Q}}_{13}^{*} \varepsilon_{z \eta} \\
& \sigma_{z \eta}=\overline{\mathrm{Q}}_{13}^{*} \varepsilon_{z z}+\overline{\mathrm{Q}}_{33}^{*} \varepsilon_{z \eta}
\end{aligned}
$$

and

- For vertical walls: -

$$
\begin{aligned}
& \sigma_{z z}=\vec{Q}_{11}^{*} \varepsilon_{z z}+\vec{Q}_{13}^{*} \varepsilon_{z \zeta} \\
& \sigma_{z \eta}=\vec{Q}_{13}^{*} \varepsilon_{z z}+\vec{Q}_{33}^{*} \varepsilon_{z \zeta}
\end{aligned}
$$

Note: The stress-strain relations for the plies of the beam walls, as given by relations (17), (18) and (21), (22) for both methods have the same shape except for the 
stiffness coefficients which are changed from the ply stiffness coefficients into modified ply stiffness coefficient.

\section{Method 3:}

This method treats the transverse in-plane behavior in a more refined manner. Conditions on the in-plane stresses and strains are imposed such that there are no in-plane forces or moments, In order to keep the formulation of the presented analytical model within the context of the beam theory, the following conditions are imposed on the transverse in-plane normal stresses: -

$$
\begin{aligned}
& \iint \sigma_{y} \mathrm{dA}=0 \\
& \iint \sigma_{\mathrm{y}} \eta \mathrm{dA}=0 \\
& \iint \sigma_{\mathrm{y}} \zeta \mathrm{dA}=0
\end{aligned}
$$

This is equivalent to setting the resultant in-plane transverse force and in-plane bending moments due to transverse normal stress to be zero. The transverse inplane strain, $\varepsilon_{y}$, is determined to satisfy these conditions. In order to prescribe $\varepsilon_{y}$, this strain must be written in general form as a continuous function within the crosssection.

$$
\varepsilon_{y}=f_{w^{\prime}} w^{\prime}+f_{u^{\prime \prime}} u^{\prime \prime}+f_{v^{\prime \prime}} v^{\prime \prime}+f_{\gamma_{z x}^{0}} \gamma_{z x}^{0}{ }^{\prime}+f_{\gamma_{y y}^{\prime}} \gamma_{z y}^{0}{ }^{\prime}+f_{\varphi^{\prime}} \varphi^{\prime}+f_{\varphi^{\prime \prime}} \varphi^{\prime \prime}
$$

Where the coefficients of the deformation are linear functions within the crosssection; i.e.

$$
\begin{aligned}
& f_{w^{\prime}}=a_{0}+a_{1} \eta+a_{2} \zeta \\
& f_{u^{\prime \prime}}=b_{0}+b_{1} \eta+b_{2} \zeta \\
& f_{v^{\prime \prime}}=c_{0}+c_{1} \eta+c_{2} \zeta \\
& f_{\gamma_{x x}^{\prime \prime}}=d_{0}+d_{1} \eta+d_{2} \zeta \\
& f_{\gamma_{y y}^{\prime \prime}}=e_{o}+e_{1} \eta+e_{2} \zeta \\
& f_{\varphi^{\prime}}=f_{0}+f_{1} \eta+f_{2} \zeta \\
& f_{\varphi^{\prime \prime}}=g_{0}+g_{1} \eta+g_{2} \zeta
\end{aligned}
$$

The constants $a_{0}, a_{1}, a_{2}$ etc. are determined from the three conditions on the in-plane stresses (equations $(23 a),(23 b)$ and $(23 c)$ ). Once the in-plane strain function is fully determined in terms of the elastic constants and cross-section geornetry, $\varepsilon_{y}$ is removed from the constitutive relations, e.g. (15), by substitution.

Note: $\varepsilon_{x x}$ in beam notation is equivalent to $\varepsilon_{y}$ in ply notation.

By substituting the strain-displacement relations, eq ${ }^{\text {s }}(12),(13)$ and (14) into the stress-strain relations, as expressed for each method, the stresses within bearn walls can be related to the displacements of the box-beam cross-section. The resultant forces and moments acting over the cross-section can be related to the stresses in the beam walls from the following equilibrium conditions: -

- Axial force

$$
\mathrm{F}_{\mathrm{z}}=\iint \sigma_{\mathrm{zz}} \mathrm{dA}
$$


- Shear forces

$$
\begin{aligned}
& F_{x}=\iint \sigma_{z \eta} d A \\
& F_{y}=\iint \sigma_{z \zeta} d A
\end{aligned}
$$

- Torque moment

$$
\mathrm{M}_{\mathrm{z}}=\iint\left[\left(\eta-\frac{\partial \omega}{\partial \zeta}\right) \sigma_{z \zeta}-\left(\zeta-\frac{\partial \omega}{\partial \eta}\right) \sigma_{z \eta}\right] \mathrm{dA}+\frac{\partial}{\partial z}\left[\iint \omega \sigma_{z z} \mathrm{dA}\right]
$$

- Bending moments

$$
\begin{aligned}
& \mathrm{M}_{\mathrm{x}}=\iint \sigma_{\mathrm{zz}} \zeta \mathrm{dA} \\
& \mathrm{M}_{\mathrm{y}}=\iint \sigma_{\mathrm{zz}} \eta \mathrm{dA}
\end{aligned}
$$

By substituting, the expressions of stresses in terms of the displacements, the system of differential equations relating the loads on the box-beam cross-section to the displacements of the beam cross-section (stretching, shearing, bending and twisting) are obtained. In matrix form, this can be written as:

and

$$
\left.\left\{\begin{array}{l}
F_{z} \\
F_{x} \\
F_{y} \\
M_{z} \\
M_{x} \\
M_{y}
\end{array}\right\}=\left[\begin{array}{cccccc}
K_{11} & K_{12} & K_{13} & K_{14} & 0 & 0 \\
K_{21} & K_{22} & 0 & 0 & K_{15} & 0 \\
K_{31} & 0 & K_{33} & 0 & 0 & K_{36} \\
K_{41} & 0 & 0 & K_{44} & K_{45} & K_{46} \\
0 & K_{52} & 0 & K_{54} & K_{55} & 0 \\
0 & 0 & K_{63} & K_{64} & 0 & K_{66}
\end{array}\right]\left\{\begin{array}{c}
w^{\prime} \\
\gamma_{x y}^{0} \\
\gamma_{y z}^{0} \\
\varphi^{\prime} \\
\left(u^{\prime}-\gamma_{x y}^{0}{ }^{\prime}\right. \\
v^{\prime}-\gamma_{y z}^{0}
\end{array}\right)\right\}
$$

$\mathrm{K}_{21}=\mathrm{K}_{12} ; \mathrm{K}_{31}=\mathrm{K}_{13} ; \mathrm{K}_{41}=\mathrm{K}_{14}$

$\mathrm{K}_{52}=\mathrm{K}_{25}$

$\mathrm{K}_{63}=\mathrm{K}_{36}$

$\mathrm{K}_{54}=\mathrm{K}_{45} ; \mathrm{K}_{64}=\mathrm{K}_{46}$

Therefore, the stiffness matrix $[\mathrm{K}]$ of the composite box-beam is symmetric. The expressions for the elements of the matrix are derived for each of the presented
methods.

From this system of differential equations, the displacements of the composite boxbeam can be determined if the applied forces and moments are known. From the beam displacements the strains and stresses on the box-beam walls can be determined and finally, the ply stresses and strains can be calculated on each wall.

\section{SPECIAL CASES ON COMPOSITE BOX-BEAM}

\subsection{Cross-Ply Layup box-beam}

In the cross-ply layup all laminates (bottom, top and two flanges are composed of alternating plies at 0 and 90 degrees. This laminates formation of the box-beam does not display any elastic coupling since: $\overline{\mathrm{Q}}_{13}=0 ; \overline{\mathrm{Q}}_{12}=0$ and $\overline{\mathrm{Q}}_{23}=0$.

Therefore, 
$\begin{array}{lll}\mathrm{K}_{12}=0 & ; & \mathrm{K}_{15}=0 \\ \mathrm{~K}_{25}=0 & \mathrm{~K}_{36}=0 & ;\end{array} \quad \begin{aligned} & \mathrm{K}_{14}=0 \\ & \mathrm{~K}_{45}=0\end{aligned}$

$\mathrm{K}_{25}=0 \quad ; \quad \mathrm{K}_{36}=0 \quad ; \quad \mathrm{K}_{45}=0$

And the remaining non-zero stiffness elements are:-

$\mathrm{K}_{11} ; \mathrm{K}_{22} ; \mathrm{K}_{33} ; \mathrm{K}_{44} ; \mathrm{K}_{55} ; \mathrm{K}_{66}$

The system of differential equations will be:-

$$
\left\{\begin{array}{l}
\mathrm{F}_{\mathrm{z}} \\
\mathrm{F}_{\mathrm{x}} \\
\mathrm{F}_{\mathrm{y}} \\
\mathrm{M}_{\mathrm{z}} \\
\mathrm{M}_{\mathrm{x}} \\
\mathrm{M}_{\mathrm{y}}
\end{array}\right\}=\left[\begin{array}{cccccc}
\mathrm{K}_{11} & 0 & 0 & 0 & 0 & 0 \\
0 & \mathrm{~K}_{22} & 0 & 0 & 0 & 0 \\
0 & 0 & \mathrm{~K}_{33} & 0 & 0 & 0 \\
0 & 0 & 0 & \mathrm{~K}_{44} & 0 & 0 \\
0 & 0 & 0 & 0 & \mathrm{~K}_{55} & 0 \\
0 & 0 & 0 & 0 & 0 & \mathrm{~K}_{66}
\end{array}\right]\left\{\begin{array}{c}
\mathrm{w}^{\prime} \\
\gamma_{\mathrm{xy}}^{0} \\
\gamma_{\mathrm{yz}}^{0} \\
\varphi^{\prime} \\
\left(\mathrm{u}^{\prime}-\gamma_{\mathrm{xy}}^{0}{ }^{\prime}\right. \\
\mathrm{v}^{\prime}-\gamma_{\mathrm{yz}}^{\mathrm{o}}
\end{array}\right\}
$$

Or it can be written as independent equations:

$\begin{array}{lll}\mathrm{F}_{\mathrm{z}}=\mathrm{K}_{11} \mathrm{w}^{\prime} \quad ; & \mathrm{F}_{\mathrm{x}}=\mathrm{K}_{22} \gamma_{\mathrm{xz}}^{0} \quad ; \quad \mathrm{F}_{\mathrm{y}}=\mathrm{K}_{33} \gamma_{\mathrm{yz}}^{0} \\ \mathrm{M}_{\mathrm{z}}=\mathrm{K}_{44} \varphi \quad ; \quad \mathrm{M}_{\mathrm{x}}=\mathrm{K}_{55}\left(\mathrm{u}^{\prime}-\gamma_{\mathrm{xz}}^{0}\right) \quad ; \quad \mathrm{M}_{\mathrm{y}}=\mathrm{K}_{66}\left(\mathrm{v}^{\prime}-\gamma_{\mathrm{yz}}^{\circ}\right)\end{array}$

\subsection{Symmetric layup box-beam}

In the symmetric layup, the top and bottom laminates are the same, and each laminate individually need not to be symmetric. The composite box-bearn will display bending-torsion coupling and extension-shear coupling and/or bending shear coupling. Therefore:

$\mathrm{K}_{14}=0 \quad ; \quad \mathrm{K}_{25}=0 \quad ; \quad \mathrm{K}_{36}=0$

And the remaining non-zero stiffness elements are: -

$\mathrm{K}_{11} ; \mathrm{K}_{12} ; \mathrm{K}_{13} ; \mathrm{K}_{22} ; \mathrm{K}_{33}$

and

$\mathrm{K}_{44} ; \mathrm{K}_{45} ; \mathrm{K}_{46} ; \mathrm{K}_{55} ; \mathrm{K}_{66}$

in such case, the system of differential equations, Eq(27), can be splitted into two systems of differential equations:

$$
\left\{\begin{array}{l}
\mathrm{F}_{\mathrm{z}} \\
\mathrm{F}_{\mathrm{x}} \\
\mathrm{F}_{\mathrm{y}}
\end{array}\right\}=\left[\begin{array}{ccc}
\mathrm{K}_{11} & \mathrm{~K}_{12} & \mathrm{~K}_{13} \\
\mathrm{~K}_{12} & \mathrm{~K}_{22} & 0 \\
\mathrm{~K}_{13} & 0 & \mathrm{~K}_{33}
\end{array}\right]\left\{\begin{array}{c}
\mathrm{w} \\
\gamma_{\mathrm{xz}}^{0} \\
\gamma_{\mathrm{yz}}^{0}
\end{array}\right\}
$$

And

$$
\left.\left\{\begin{array}{l}
M_{z} \\
M_{x} \\
M_{y}
\end{array}\right\}=\left[\begin{array}{llc}
K_{44} & K_{45} & K_{46} \\
K_{45} & K_{55} & 0 \\
K_{46} & 0 & K_{66}
\end{array}\right]\left\{\begin{array}{c}
\varphi^{\prime} \\
\left(u^{\prime}-\gamma_{x z}^{0} !\right. \\
v^{\prime}-\gamma_{y z}^{0} \backslash
\end{array}\right)\right\}
$$

It should be noted that the bending and torsion of the box-beam is not elastically coupled to the extension and shearing of the beam. 


\section{EVALUATION \& VALIDATION OF THE ANALYSIS}

For the verification of the presented theory numerical results are compared for a cantilever box-beam cross-section [11], made of E-glass/epoxy and tested under bending and torsion. The dimensions of the thin-walled cross-section are as follows: flange width $49.5(\mathrm{~mm})$, web height $107.9(\mathrm{~mm})$, flange thickness $5.4(\mathrm{~mm})$, and web thickness $1.8(\mathrm{~mm})$. The flange laminate is $\left[(0 / 90)_{5} /(45 /-45)_{2}\right]_{\mathrm{s}}$ and the web laminate is $\left[(45 /-45)_{2}\right]_{s}$. The beam geometry as well as the location of the strain gauges is shown in Fig (2). The measurements are compared to the theoretical calculations based on equation (34) and (35). Fig.(3) shows the strain distribution along the beam length due to a shear force equal to $490.5 \mathrm{~N}$ applied at the free end of the beam. It causes the case of simple bending on the cantilever box-beam. The figure shows the comparison between the measured values as mentioned in ref [11] and the calculated values by the presented three methods. Table (1) shows the strain due to different shear force values at the free end at the location (6), Fig (2), as given from measurement, ref [11] and the calculated methods presented here.

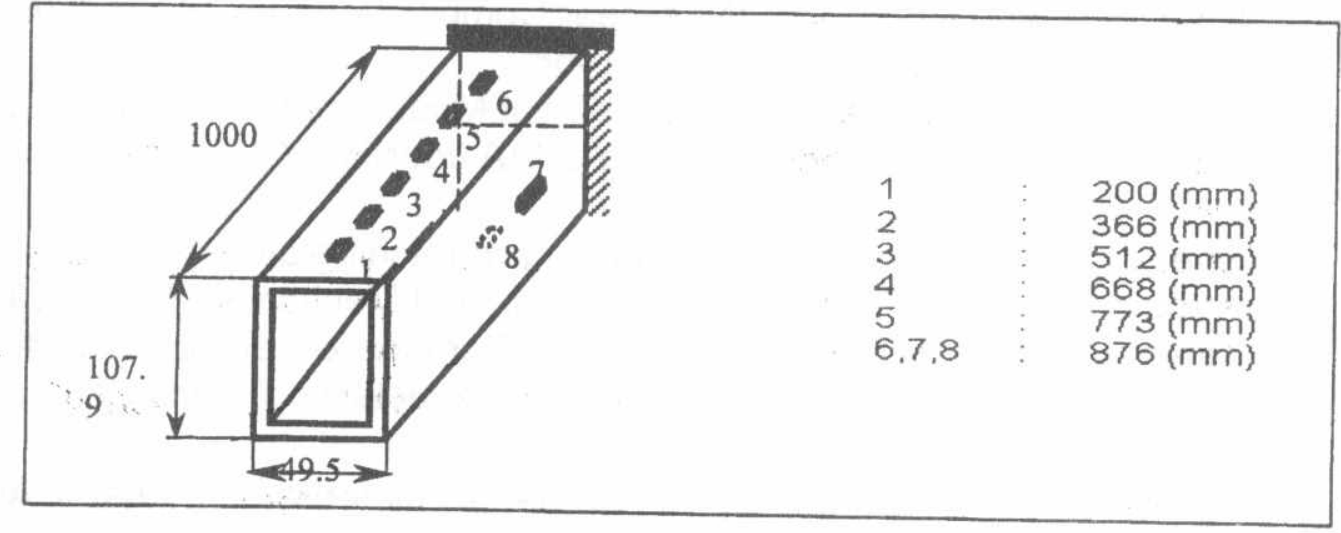

Fig (2) : Strain gauges position from free end

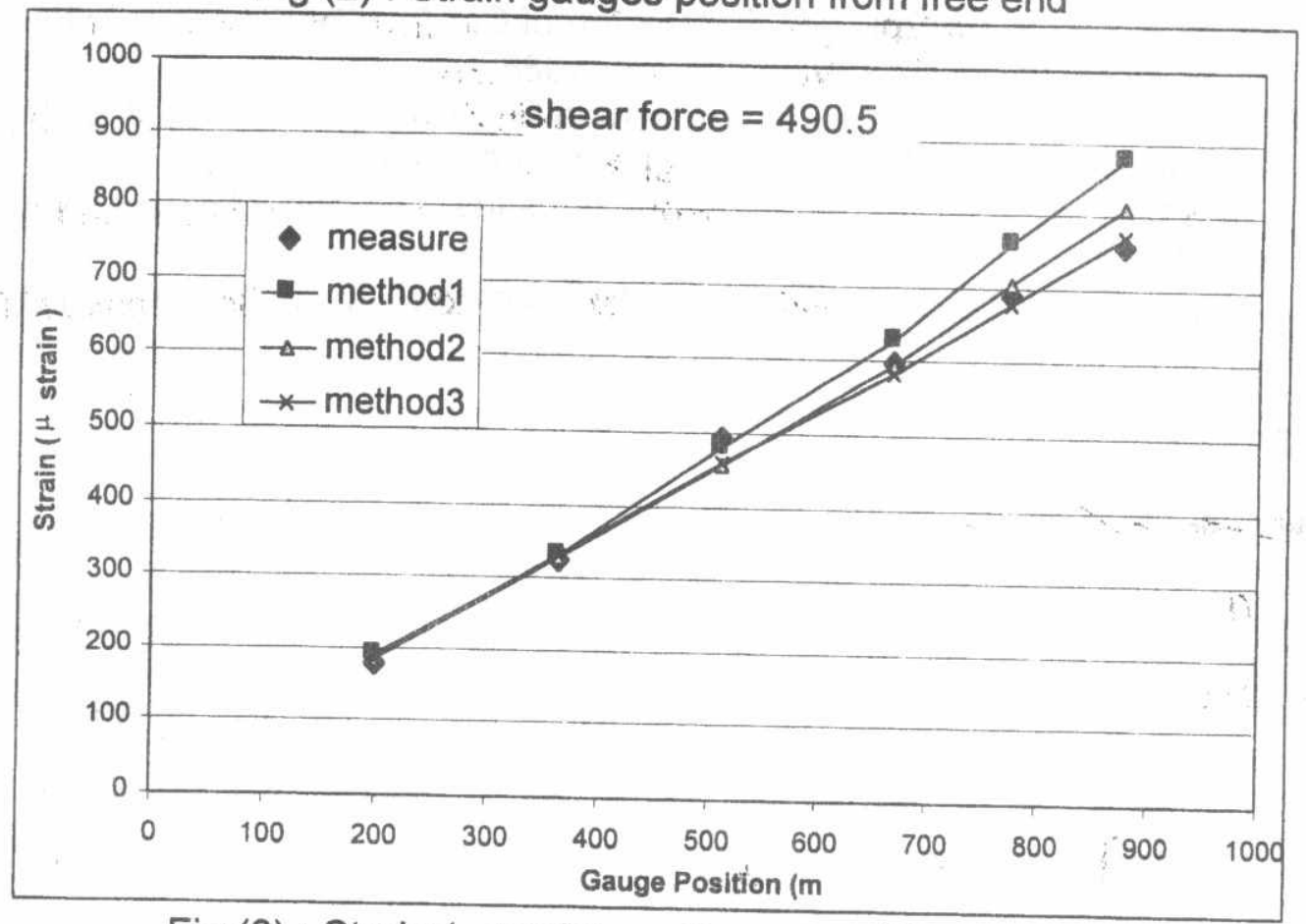

Fig (3) : Strain ( $\mu$ strain) vs. Gauge position $(\mathrm{mm})$ for 
Table. Strain at location $(\mathrm{mm})(6)$ vs. Load (N)

\begin{tabular}{|c|c|c|c|c|}
\hline load & measured & method1 & method2 & method3 \\
\hline 98.1 & 167.135 & 164.95 & 162.3471 & 166.2671 \\
\hline 196.2 & 310.965 & 309.90 & 312.3215 & 314.6216 \\
\hline 294.3 & 458.716 & 464.86 & 469.0371 & 462.3147 \\
\hline 392.4 & 608.163 & 619.81 & 621.2672 & 610.1873 \\
\hline 490.5 & 757.602 & 774.76 & 778.1246 & 769.3184 \\
\hline
\end{tabular}

\section{References}

[1] Giavoto, V, Borri,M, et al. "Anisotropic Beam Theory and Applications" Journal Of Computers \& Structures, Vol 16, 1983.

[2] Bauchau, O.A, and Hong C.H,"Large Displacement Analysis of Naturally Curved and Twisted Composite Beams", AIAA Journal, Vol. 25, October 1987.

[3] Bauchau, O.A, and Hong C.H, "Nonlinear Composite Beam Theory", Journal of Applied Mechanics, Vol. 55, March 1988.

[4] Stemple, A.D. and Lee, S.W, "Finite Element Model For Composite Beams With Arbitrary Cross-Sectional Warping",AIAA Journal, Vol. 26, Decernber 1988.

[5] Reissner, E. and Tsai, W.T., "Pure Bending, Stretching and Twisting of Anisotropic Cylindrical Shells", Journal of Applied Mechanics, March 1972.

[6] Mansfield, E.H. and Sobey A.J., "The Fiber Composite Helicopter Blade; Part 1; Stiffness Properties; Part 2; Prospects for Aeroelastic Tailoring", Aeronautical Quarterly, May 1979.

[7] Bauchau, O.A., "A Beam Theory for Anisotropic Materials", Journal of Applied Mechanics, Vol. 20, January 1985.

[8] Bicos, A.S., and Springer, G.S., "Design of Cor.posite Box-Beam" ,Journal of Composite Materials, Vol. 20, January $198 \%$.

[9] Libove, C. "Stresses and Rate of Twisi in Single-Cell Thin-Walled Beams with Anisotropic Walls", AIAA Journal vol.26, September 1988.

[10] Datoo,M.H, "Mechanics of Fir uus Composites" , Elsevier Applied Sciences, 1991.

[11] Temerik M.T, " Comporie Thin-Waked Structures", M.Sc. Thesis, MTC, 1997.

\section{APPENDIX A}

$$
\begin{aligned}
& \text { Stiffens fo nethod } 1 \\
& \mathrm{~K}_{11}=\iint_{, \mathrm{v}} \overline{\mathrm{Q}}_{11} \mathrm{dA} \\
& \mathrm{K}_{12}=\iint_{\mathrm{Q}} \overline{\mathrm{Q}}_{13} \mathrm{dA} \\
& \mathrm{K}_{13}=\iint_{\mathrm{Q}} \overline{\mathrm{Q}}_{13} \mathrm{dA} \\
& \mathrm{K}_{14}=-(1+\beta) \iint_{\mathrm{d}} \overline{\mathrm{Q}}_{13} \zeta \mathrm{dA}+(1-\beta) \iint_{\mathrm{V}} \overline{\mathrm{Q}}_{13} \eta \mathrm{dA}
\end{aligned}
$$




$$
\begin{aligned}
& \mathrm{K}_{22}=\iint_{h} \overline{\mathrm{Q}}_{33} \mathrm{dA} \\
& \mathrm{K}_{25}=\iint_{\mathrm{Q}} \overline{\mathrm{Q}}_{13} \zeta \mathrm{dA} \\
& \mathrm{K}_{33}=\iint_{V} \overline{\mathrm{Q}}_{33} \mathrm{dA} \\
& \mathrm{K}_{36}=\iint_{V} \overline{\mathrm{Q}}_{13} \eta \mathrm{dA} \\
& \mathrm{K}_{14}=(1+\beta)^{2} \iint_{h} \overline{\mathrm{Q}}_{33} \zeta^{2} \mathrm{dA}+(1-\beta)^{2} \iint_{V} \overline{\mathrm{Q}}_{33} \eta^{2} \mathrm{dA} \\
& \mathrm{K}_{45}=(1+\beta) \iint_{\mathrm{Q}} \overline{\mathrm{Q}}_{13} \zeta^{2} \mathrm{dA} \\
& \mathrm{K}_{46}=-(1-\beta) \iint_{V} \overline{\mathrm{Q}}_{13} \eta^{2} \mathrm{dA} \\
& \mathrm{K}_{55}=\iint_{h, \mathrm{v}} \overline{\mathrm{Q}}_{11} \zeta^{2} \mathrm{dA} \\
& \mathrm{K}_{66}=\iint_{h, \mathrm{v}} \overline{\mathrm{Q}}_{11} \eta^{2} \mathrm{dA}
\end{aligned}
$$

\section{Stiffness for method 2}

$$
\begin{aligned}
& \mathrm{K}_{11}=\iint_{\mathrm{h}, \mathrm{v}}\left(\overline{\mathrm{Q}}_{11}-\frac{\overline{\mathrm{Q}}_{12}^{2}}{\overline{\mathrm{Q}}_{22}}\right) \mathrm{dA} \\
& \mathrm{K}_{12}=\iiint_{\mathrm{L}}\left(\overline{\mathrm{Q}}_{13}-\frac{\overline{\mathrm{Q}}_{12} \overline{\mathrm{Q}}_{23}}{\overline{\mathrm{Q}}_{22}}\right) \mathrm{dA} \\
& \mathrm{K}_{13}=\iint\left(\overline{\mathrm{Q}}_{13}-\frac{\overline{\mathrm{Q}}_{12} \overline{\mathrm{Q}}_{23}}{\overline{\mathrm{Q}}_{22}}\right) \mathrm{dA} \\
& \mathrm{K}_{14}=-(1+\beta) \iint_{\mathrm{h}}\left(\overline{\mathrm{Q}}_{13}-\frac{\overline{\mathrm{Q}}_{12} \overline{\mathrm{Q}}_{23}}{\overline{\mathrm{Q}}_{22}}\right) \zeta \mathrm{dA}+(1-\beta) \iint_{\mathrm{v}}\left(\overline{\mathrm{Q}}_{13}-\frac{\overline{\mathrm{Q}}_{12} \overline{\mathrm{Q}}_{23}}{\overline{\mathrm{Q}}_{22}}\right) \eta \mathrm{dA} \\
& \mathrm{K}_{22}=\iint_{\mathrm{L}}\left(\overline{\mathrm{Q}}_{33}-\frac{\overline{\mathrm{Q}}_{23}^{2}}{\overline{\mathrm{Q}}_{22}}\right) \mathrm{dA} \int_{\mathrm{h}}\left(\overline{\mathrm{Q}}_{13}-\frac{\overline{\mathrm{Q}}_{12} \overline{\mathrm{Q}}_{23}}{\overline{\mathrm{Q}}_{22}}\right) \zeta \mathrm{dA} \\
& \mathrm{K}_{33}=\iint_{\mathrm{V}}\left(\overline{\mathrm{Q}}_{33}-\frac{\overline{\mathrm{Q}}_{23}^{2}}{\overline{\mathrm{Q}}_{22}}\right) \mathrm{dA} \\
& \mathrm{K}_{36}=\iint_{\mathrm{v}}\left(\overline{\mathrm{Q}}_{13}-\frac{\overline{\mathrm{Q}}_{12} \overline{\mathrm{Q}}_{23}}{\overline{\mathrm{Q}}_{22}}\right) \eta \mathrm{dA} \\
& \mathrm{K}_{44}=(1+\beta)^{2} \iint_{\mathrm{h}}\left(\overline{\mathrm{Q}}_{33}-\frac{\overline{\mathrm{Q}}_{23}^{2}}{\overline{\mathrm{Q}}_{22}}\right) \zeta^{2} \mathrm{dA}+(1-\beta)^{2} \iint_{\mathrm{v}}\left(\overline{\mathrm{Q}}_{33}-\frac{\overline{\mathrm{Q}}_{23}^{2}}{\overline{\mathrm{Q}}_{22}}\right) \eta^{2} \mathrm{dA}
\end{aligned}
$$




$$
\begin{aligned}
& \mathrm{K}_{45}=(1+\beta) \iint_{\mathrm{h}}\left(\overline{\mathrm{Q}}_{13}-\frac{\overline{\mathrm{Q}}_{12} \overline{\mathrm{Q}}_{23}}{\overline{\mathrm{Q}}_{22}}\right) \zeta^{2} \mathrm{dA} \\
& \mathrm{K}_{46}=-(1-\beta) \iint_{\mathrm{v}}\left(\overline{\mathrm{Q}}_{13}-\frac{\overline{\mathrm{Q}}_{12} \overline{\mathrm{Q}}_{23}}{\overline{\mathrm{Q}}_{22}}\right) \eta^{2} \mathrm{dA} \\
& \mathrm{K}_{55}=\iint_{\mathrm{h}, \mathrm{v}}\left(\overline{\mathrm{Q}}_{11}-\frac{\overline{\mathrm{Q}}_{12}^{2}}{\overline{\mathrm{Q}}_{22}}\right) \zeta^{2} \mathrm{dA} \\
& \mathrm{K}_{66}=\iint_{\mathrm{h}, \mathrm{v}}\left(\overline{\mathrm{Q}}_{11}-\frac{\overline{\mathrm{Q}}_{12}^{2}}{\overline{\mathrm{Q}}_{22}}\right) \eta^{2} \mathrm{dA}
\end{aligned}
$$

\section{Stiffness for method 3}

$$
\begin{aligned}
& \mathrm{K}_{11}=\iint_{\mathrm{h}, \mathrm{v}} \overline{\mathrm{Q}}_{11} \mathrm{dA}-\frac{\iint_{\mathrm{h}, \mathrm{v}} \overline{\mathrm{Q}}_{12} \mathrm{dA} \iint_{\mathrm{h}, \mathrm{v}} \overline{\mathrm{Q}}_{12} \mathrm{dA}}{\iint_{\mathrm{h}, \mathrm{v}} \overline{\mathrm{Q}}_{22} \mathrm{dA}} \\
& \mathrm{K}_{12}=\iint_{\mathrm{h}} \overline{\mathrm{Q}}_{13} \mathrm{dA}-\frac{\iint_{\mathrm{h}} \overline{\mathrm{Q}}_{23} \mathrm{dA} \iint_{\mathrm{h}} \overline{\mathrm{Q}}_{12} \mathrm{dA}}{\iint_{\mathrm{h}} \overline{\mathrm{Q}}_{22} \mathrm{dA}} \\
& K_{13}=\iint_{V} \bar{Q}_{13} d A-\frac{\iint_{v} \bar{Q}_{23} d A \iint_{v} \bar{Q}_{12} d A}{\iint_{V} \bar{Q}_{22} d A} \\
& \mathrm{~K}_{14}=-(1+\beta) \iint_{\mathrm{Q}} \overline{\mathrm{Q}}_{13} \zeta \mathrm{dA}+(1+\beta) \iint_{V} \overline{\mathrm{Q}}_{13} \eta \mathrm{dA} \\
& +\frac{(1+\beta) \iint_{\mathrm{h}} \overline{\mathrm{Q}}_{23} \zeta \mathrm{dA}-(1-\beta) \iint_{\mathrm{Q}} \overline{\mathrm{Q}}_{23} \eta \mathrm{dA}}{\iint_{\mathrm{h}, \mathrm{v}} \overline{\mathrm{Q}}_{22} \mathrm{dA}} \iint_{\mathrm{h}, \mathrm{v}} \overline{\mathrm{Q}}_{12} \mathrm{dA} \\
& \mathrm{K}_{22}=\iint_{\mathrm{h}} \overline{\mathrm{Q}}_{33} \mathrm{dA}-\frac{\iint_{\mathrm{h}} \overline{\mathrm{Q}}_{23} \mathrm{dA} \iint_{\mathrm{h}} \overline{\mathrm{Q}}_{23} \mathrm{dA}}{\iint_{\mathrm{h}} \overline{\mathrm{Q}}_{22} \mathrm{dA}} \\
& \mathrm{K}_{25}=\iint_{\mathrm{h}} \overline{\mathrm{Q}}_{13} \zeta \mathrm{dA}-\frac{\iint_{\mathrm{h}} \overline{\mathrm{Q}}_{23} \zeta \mathrm{dA} \iint_{\mathrm{h}} \overline{\mathrm{Q}}_{12} \mathrm{dA}}{\iint_{\mathrm{h}} \overline{\mathrm{Q}}_{22} \mathrm{dA}} \\
& \mathrm{K}_{33}=\iint_{\mathrm{v}} \overline{\mathrm{Q}}_{33} \mathrm{dA}-\frac{\iint_{\mathrm{v}} \overline{\mathrm{Q}}_{23} \mathrm{dA} \iint_{\mathrm{v}} \overline{\mathrm{Q}}_{23} \mathrm{dA}}{\iint_{\mathrm{V}} \overline{\mathrm{Q}}_{22} \mathrm{dA}} \\
& \mathrm{K}_{36}=\iint_{\mathrm{v}} \overline{\mathrm{Q}}_{13} \eta \mathrm{dA}-\frac{\iint_{\mathrm{v}} \overline{\mathrm{Q}}_{23} \eta \mathrm{dA} \iint_{\mathrm{v}} \overline{\mathrm{Q}}_{12} \mathrm{dA}}{\iint_{\mathrm{V}} \overline{\mathrm{Q}}_{22} \mathrm{dA}}
\end{aligned}
$$


Proceedings of the $8^{\text {th }}$ ASAT Conference, 4-6 May 1999

Paper SM-17

455

$$
\begin{aligned}
& \mathrm{K}_{44}=(1+\beta)^{2} \iint_{\mathrm{Q}} \overline{\mathrm{Q}}_{33} \zeta^{2} \mathrm{dA}+(1-\beta)^{2} \iint_{\mathrm{V}} \overline{\mathrm{Q}}_{33} \eta^{2} \mathrm{dA} \\
& +\frac{(1+\beta) \iint_{11} \overline{\mathrm{Q}}_{23} \zeta \mathrm{dA}-(1-\beta) \iint_{\mathrm{Q}_{23}} \eta \mathrm{dA}}{\iint_{\mathrm{d}, \mathrm{V}} \overline{\mathrm{Q}}_{22} \mathrm{dA}} \\
& \times\left[(1-\beta) \iint \overline{\mathrm{Q}}_{33} \eta \mathrm{dA}-(1+\beta) \iint_{\mathrm{Q}} \overline{\mathrm{Q}}_{23} \zeta \mathrm{dA}\right] \\
& \mathrm{K}_{45}=(1+\beta) \iint_{h} \overline{\mathrm{Q}}_{13} \zeta^{2} \mathrm{dA}-\frac{(1+\beta) \iint_{\mathrm{a}} \overline{\mathrm{Q}}_{23} \zeta^{2} \mathrm{dA} \iint_{\mathrm{L}, \mathrm{v}} \overline{\mathrm{Q}}_{12} \zeta^{2} \mathrm{dA}}{\iint_{\mathrm{h}, \mathrm{V}} \overline{\mathrm{Q}}_{22} \zeta^{2} \mathrm{dA}} \\
& \mathrm{K}_{46}=-(1-\beta) \iint_{\mathrm{V}} \overline{\mathrm{Q}}_{13} \eta^{2} \mathrm{dA}+\frac{(1-\beta) \iint_{\mathrm{Q}} \overline{\mathrm{Q}}_{23} \eta^{2} \mathrm{dA} \iint_{\mathrm{L}, \mathrm{v}} \overline{\mathrm{Q}}_{12} \eta^{2} \mathrm{dA}}{\iint_{\mathrm{V}} \overline{\mathrm{Q}}_{22} \eta^{2} \mathrm{dA}} \\
& \mathrm{K}_{55}=\iint_{\mathrm{h}, \mathrm{V}} \overline{\mathrm{Q}}_{11} \zeta^{2} \mathrm{dA}-\frac{\iint_{\mathrm{h}, \mathrm{v}} \overline{\mathrm{Q}}_{12} \zeta^{2} \mathrm{dA} \iint_{\mathrm{h}, \mathrm{v}} \overline{\mathrm{Q}}_{12} \zeta^{2} \mathrm{dA}}{\iint_{\mathrm{h}, \mathrm{V}} \overline{\mathrm{Q}}_{22} \zeta^{2} \mathrm{dA}} \\
& \mathrm{K}_{66}=\iint_{\mathrm{d}, \mathrm{v}} \overline{\mathrm{Q}}_{11} \eta^{2} \mathrm{dA}-\frac{\iint_{\mathrm{d}, \mathrm{V}} \overline{\mathrm{Q}}_{12} \eta^{2} \mathrm{dA} \iint_{\mathrm{d}, \mathrm{Q}} \overline{\mathrm{Q}}_{12} \eta^{2} \mathrm{dA}}{\iint_{\mathrm{A}, \mathrm{Q}} \overline{\mathrm{Q}}_{22} \eta^{2} \mathrm{dA}}
\end{aligned}
$$

